\title{
REGIONAL AIRPORT: STUDY ON ECONOMIC AND SOCIAL PROFITABILITY
}

\author{
S. AMOROSO \& L. CARUSO \\ Department of Transport Engineering, University of Palermo, Italy.
}

\section{ABSTRACT}

Using Geomatics and GIS technologies, the aim of this study is the recovery of a regional economy focused on the areas that are marginalized and depressed, or with an emerging tourist industry, to reach explanatory variables of the airport impact on the regional economy. This analysis is conducted on the basis of geographical data and socio-economic features that characterized the area taken into account.

Keywords: air transport, airport, economic profitability, regional development, social cost, social benefits.

\section{INTRODUCTION}

Next to the main activities relating to international air traffic, which absorb large flows of traffic and offer primary and supplementary services, today airport is identified by their irreplaceable role in modern economic life, especially in the connections between places that, for geographical reasons or otherwise, have the characteristics of difficult accessibility by other modes of transport and levels of demand not so high as to justify international and/or intercontinental air services.

The functionality of these services also depends on policy choices in terms of airport facilities and their distribution in the territory compared to the docks and the traffic volumes that interest them. In this respect, the analysis must be conducted according to geographical data and socio-economic features of the area taken into account, in particular, on a regional scale, the recovery in the economy of the region, and the depressed or marginalized areas emerging from tourism.

The choice of location of the airports must be made within the framework of general guidelines at the national level via the joint-state region, given that planning at the regional level, by itself, is not able to consider and assess the many aspects of the problem territories that may exceed those that are exclusively regional.

Air services outlined, included among those listed services in the short to medium range, may allow, without significant financial commitments and without complex infrastructure, the presence of air transport in urban, industrial and tourist centers, away from major airports and in large agglomerations that have a small airport.

The best prospects we have, however, are in relations to traffic to and between islands, given the slowness of shipping and the need for social and economic relations that should be frequent and fast. Besides, in addition to public interest, the social aim is more easily achieved employing the links between southern Italy and the marginal locations than the industrial and economic centers, thus facilitating the objectives of revitalizing areas socially and economically less developed.

Thus, the airport is seen as a service to the territory, similar to that of a hospital, a school or a cultural center. It is necessary, even in the case of a regional airport, to provide the area of influence and activities that allow the best and most appropriate use and development according to national and regional planning. Hence, the need to identify a methodology that allows explanatory variables of the airport to impact on the regional economy is to be reached.

(C) 2010 WIT Press, www.witpress.com

ISSN: 1743-7601 (paper format), ISSN: 1743-761X (online), http://journals.witpress.com DOI: 10.2495/SDP-V5-N2-175-184 


\section{RELATIONSHIP BETWEEN THE AIRPORT AND TERRITORY}

Airports, according to the classification proposed by the European Commission, can be divided into four categories:

1. large airports, characterized by traffic higher than 10,000,000 annual passengers;

2. national airports, with traffic between 5,000,000 and 10,000,000 annual passengers;

3. major regional airports, with traffic between $1,000,000$ and 5,000,000 annual passengers;

4. small regional airports, with less traffic, up to $1,000,000$ annual passengers.

The presence of an airport in a region can be an important strategic asset in solving problems of economic and territorial growth, it is endogenous and exogenous in nature, contributing to the supply chain, of new business, and leading to significant increase in employment.

The interdependence between the airport and the land is expressed through a relationship that can be described as 'complex and synergistic'. An airport is, in fact, able to enhance and strengthen the economy of the region in which it is located and to encourage competitiveness. Furthermore, it becomes an effective marketing tool, as far as it ensures an improvement of transport efficiency and increased attractiveness of the area concerned.

The economic impact of an airport is determined by it being at once both an economic activity in itself and as a support facility to the regional economy, capable of supporting businesses and populations of the surrounding area, and a vehicle that increases the effective 'international accessibility of the area'. This is especially true now that we see the development of services and low cost airlines, which tend to settle primarily in regional airports, where cheaper management is made possible, and with a less expensive airport infrastructure and limited congestion.

The presence of an airport can improve the proliferation of tourist activities. Improved access to an airport is an important factor and can result in the production of tourist services with advanced methods that can support significant events including those of sports, culture and congress [1].

Importantly, the interaction between the surrounding area and the airport has to take into account the main negative externalities (emissions and noise) produced by the infrastructure. Integration between the airport and the surrounding area has long been a thorny issue as a result of the dependence of the airports on national and state policies, essentially alien, or at least not very receptive to the needs of specific areas; the absence of an adequate communication with the entities more rooted in local context has meant that for a long time airports have been independent and not very coherent with the urban and regional environment. Recently there was a change in trend, characterized by a greater involvement of the strategies for airport development in the urban planning policies.

Ultimately it can be said that modern and efficient airports with high-quality services and facilities integrated with the surrounding area are the preconditions for economic development, tourism and social regeneration of their host regions.

An airport usually serves the population and supports the activities of its surrounding area identified in the literature as the 'catchment area'. In detail, the catchment area of an airport can be defined as the geographical area from which it draws passengers, or the geographical area that contains the potential users and passengers of an airport. The catchment area (or area of attraction) can distinguish between 'primary areas' and 'secondary areas', in particular related to airports which operate with low-cost airlines, whose extension is specifically related to the type of service offered [2].

With reference to only the primary area of attraction, and considering various international experiences in the field studies, it is possible to consider some important factors on which it depends, in particular:

- resident population,

- annual average income and average family income, 
- level of employment,

- fields of work.

Basically, many studies simply require knowledge of the potential attractiveness of an airport, or whether and how an airport is seen as a possible alternative. This is the case of the preliminary analysis of feasibility studies and, especially, studies of strategic planning.

In this respect it is important to refer to the catchment area and the area of influence of an airport. The first is the union of all the areas whose residents, who travel by air, choose the airport in question. The area of influence of an airport is the union of all the areas whose residents, who travel by air, view the airport under consideration as a possible alternative choice, assuming the significance of potential users in question.

The airport generates economic value on two fronts:

1. As an economic activity in itself: it is the product of the concentration of investments and the provision of services related to air traffic management, administrative management and accounting of the airport;

2. As a support facility to the regional economy, as it can provide businesses and the public with a means of quick and reliable transportation to develop business, trade and offer services that can enhance the accessibility of national, international and intercontinental area.

The vicinity of an airport capable of allowing connections to the whole European system can be a stimulus to the residential choice of location for people who are forced to travel a lot for work and whose activities are particularly skilled.

An airport is able to develop and strengthen the economy of the region in which it is located and to increase their competitiveness, thus creating a virtuous circle between airport and territory: the first is an important resource for the second, but at the same time second should be able to make necessary lifeblood to the first [3].

\section{THE SOCIAL PROFITABILITY OF A REGIONAL AIRPORT}

The problem of assessing the economic impact of the development of a regional airport on the area served by it can be addressed through a measuring instrument that goes beyond simple economic viability, and takes into account certain social aspects of the item in environment (in the widest sense) of such an infrastructure.

If at the micro level the concept of economic viability is the difference between accounting costs and revenues, reflecting quite accurately the situation is not the same at the macro level, where they cannot ignore social factors such as political, cultural and ecological ones. In general, an activity can produce different types of effects (direct and indirect), whose analysis deserves particular attention in a choice of allocating resources that go beyond simple economic accounting.

The philosophy of social profitability lies in a global problem that requires taking into account all relevant factors, including those that are considered difficult or even not measurable. It's clear that every social phenomenon must be considered and judged in relation to the overall development of the communities in which it operates. This means that each case is considered different from others and therefore requires a different solution, for example, the analysis of the social viability of an airport should be dealt with in different ways depending on whether the airport is located in the United States or Italy.

One of the reasons why we need an assessment tool, other than economic viability, is the new way of seeing the relationship between air transport systems and the environment, taking in account a 
view to the longer term, even the resistance that its environment opposes against any activity that threatens the balance.

In order to define the components of social profitability in a sufficiently general way, you can define all the social risks of damage or injury, other than purely economic, caused in the present or the future society from a political or economic point of view.

Similarly you can define all the social benefits from a certain choice of the same type. In analogy with the concept of economic viability, social profitability is expressed as the difference between social costs and benefits.

In stressing the difference between the concept of profitability and social cost-benefit analysis, while the latter is primarily a tool for a decision linked to the significant elements which may occur in the near future, the concept of social profitability is an ignored problem of discounting the future cash flows, since it is essentially there to consider and evaluate factors that occurred during a period in the past. For example, while the choice of the location of an airport is a typical problem of the cost-benefit analysis, a classic example of social profitability is that the merits or demerits of the continued operation of an airline are economically deficient.

The usefulness of social profitability and cost benefits are to offer a weight capable of giving a comprehensive view of the problems to those responsible for decisions, even if they can depart at the end from the choices recommended by the technicians.

\section{SOCIAL BENEFITS}

The regional airport is here understood as the infrastructure at the service of middle range, which determines a level of traffic that is from 1 to 5 million passengers per year. The analysis of social benefits related to a facility of this type is to be conducted under the triple point of view, for:

- individual users,

- enterprises and groups,

- the region.

The benefits at the individual level can be considered as having some major impact and can be translated into practical terms in time savings, reduction of discomfort which, in turn, to the user, mean increases in productivity and efficiency and greater ease of movement.

But one should point out that the benefits that an individual derives from the use of air transport which, however, are the main reasons of choosing the aircraft as a means of transport available only if they pay the going price. It follows that they are not social, but are an integral part of the service offered.

Regarding secondary impacts, namely those that refer to groups and businesses, it is appropriate to distinguish between groups and companies that use the system of air transport and groups and businesses that gravitate in the airport area. In the first case, several studies on the type of user for short-medium haul showed that occupational exposure was widely prevalent as the reasons for travel, which, mainly in relation to the double advantage that the company does in fact achieve a better organization, especially at higher levels, both in terms of geographical expansion and opening of new markets.

A rationale for strong growth in travel is that relating to tourism, especially in regions that have strong attractions in terms of landscape, archaeological, historical and cultural monuments in general.

The second case, in reality, is the tertiary impacts between the effects of new infrastructure on the surrounding area and more generally on the region in which they were designed. As with any 
economic activity, the study of the impact of an airport on the region served by it must, to achieve a significant degree of validity, be viewed in the context of regional policy and objectives which it seeks.

Among the tertiary impacts, the location of businesses in the vicinity of the airport, to be considered as a pole of development, and the subsequent creation of new jobs are the main effects to be considered in relation to the implementation of the airport. But while it is fairly easy to identify the different types of jobs created (closely related to the air transport system, or related services gravitating around the airport and businesses attracted to the hub airport, or related to the increase regional economic activity), much more difficult is the choice of a criterion that allows the quantitative assessment in relation to the characteristics, needs and objectives of each region. In any case, it should be noted that the airport is not an element in the economic and social growth of a region together with several others, such as the level of the global transport system, the cost of land, tax breaks and financial availability, labor costs and transport of raw materials and finished products.

The airport produces services intermediaries and in this sense the work is closely related to the level of global economic region. It is only in the second line that it serves as a stimulator at a regional level. In this incentive it should be recalled that the airport is but one among many possible choices. Hence the need to consider including the question of opportunity cost between the various initiatives proposed incentive.

Among the tertiary impacts, the complementary roles that take place at an airport should be included in additional to air services, which is the first vocation of these facilities. We refer not only to services but also gravitating over to the function of the reception center for tourists, the meeting point for businessmen, not to mention the strategic importance that should be recognized [4].

\subsection{Externalities}

In the case of air operations, when it comes to social costs it refers almost exclusively to the phenomena of noise and air pollution. These phenomena, if they have taken on a particularly acute significance for aviation airports typical type $\mathrm{A}$ and $\mathrm{B}$, are much less felt in the case of services to airports that are type $\mathrm{C}$ and $\mathrm{D}$, since the emission of noise and gas pollutants of the means employed in this field are well below the more restrictive standard, it follows that the cost elements associated with them are considered negligible.

The philosophy of the concept of social profitability requires that the public, as a social cost as they are, are without doubt, a burden to taxpayers. Although this is not a social cost itself, it is mentioned in this paragraph as the concept of opportunity cost, already introduced.

This concept is intimately linked to that of choice, because its function is crucial to assess the inputs and outputs of any business. In the case of a regional airport, the 'input' is essentially made of occupied area, energy, raw materials, financial contributions, while the 'output' can be identified in income, jobs, new industries and general economic growth of the region concerned.

The concept of cost-opportunity makes it possible to determine, in our particular case, if a choice different from that of the airport would not be possible to obtain outputs of greater value, for the same inputs needed, with the ultimate goal of maximizing the value added of the latter.

It is therefore desirable to first ascertain the greater or lesser availability of inputs, resulting in second place, to what extent the economic growth created by the airport is consistent with the overall policies at both national and regional levels. 
From this point of view it is important to consider whether the 'output' is certain to meet the needs of the region so as to make the best use of its availability and fit smoothly into its economic policy, while taking into account the present context.

\section{REGIONAL AIRPORT: THE ECONOMIC AND SOCIAL ASPECTS}

Based on the above, the study of economic and social viability of a regional airport can be summarized according to logical operating components (Fig. 1).
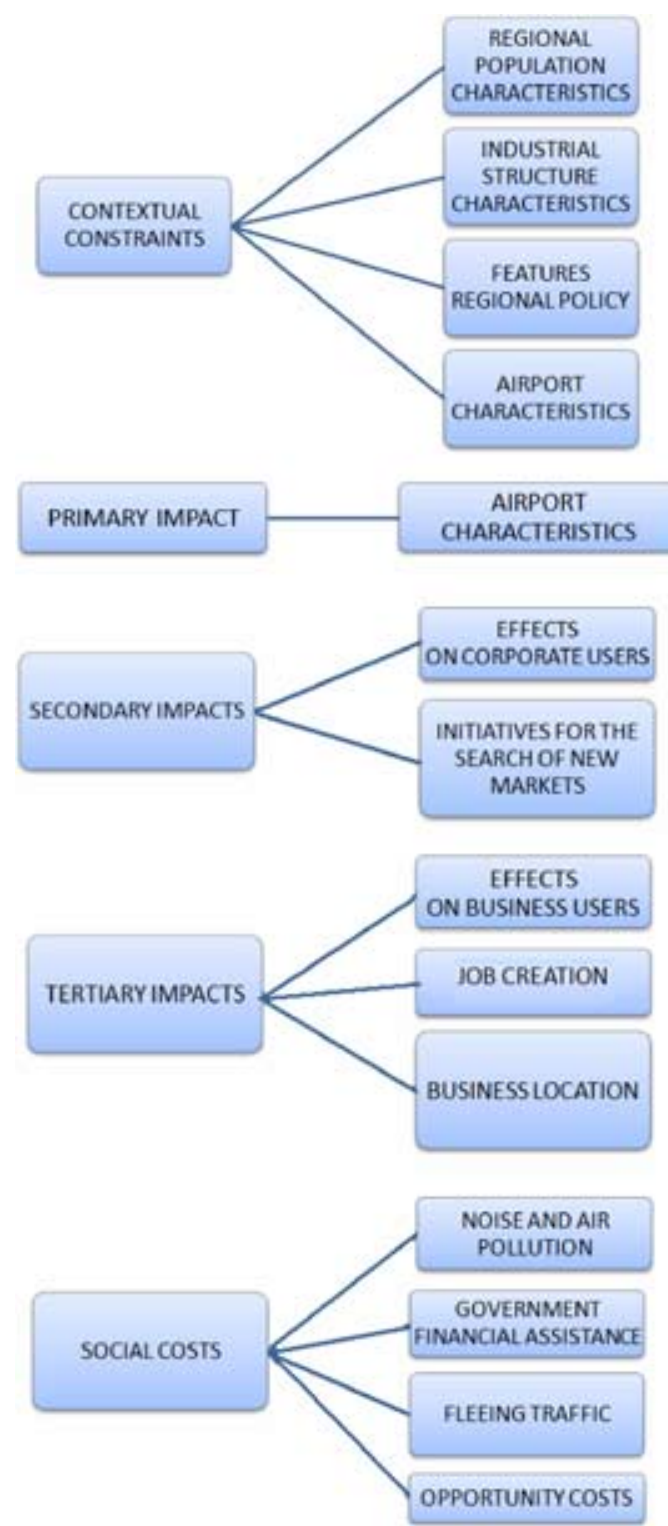

Figure 1: Logical scheme of work. 
As already mentioned, the first step is the analysis of environmental constraints in the sense that each phenomenon should be studied in relation to the overall development of the communities in which it must fit.

In this vision the characteristic of the regional population (birth and mortality rate, rate of emigration and immigration, distribution of population according to different criteria and in particular social status and sector of activity) should be considered. Also, the characteristics of regional industrial structure (evolution of industrial production, determination of the industries whose growth rate is above average, the type of industries that best meet the needs of the region, development of a hierarchy in favor of the priority areas) and the characteristics of regional policy (policy passed, current policy in terms of objectives, airport policy choice, etc.).

After performing the analysis of external conditions, attention should be turned to those that are the special characteristics of the airport, in particular, the inter-relationship between the airport infrastructure and its hinterland should be considered, with the consequent delimitation of its basin user based on the distribution of areas and geo-economic context in which the infrastructure is inserted, the possible situation of competition with other airports, the possible existence of regulatory and legal difficulties, on the right of traffic or technical limitations.

The effects on users of air transport, those who have defined the primary impacts, are the subject of the second step in the methodology adopted for the study of economic and social returns.

Bearing in mind the considerations made previously, in this regard, it is worthwhile to note here that the analysis must consider the various aspects. Use of air travelers, such as the degree of satisfaction on the service, the social condition of the user, the business sector, the motivation of movements, frequency of travel to certain destinations, and so on.

The main purposes of this analysis are determining the propensity to choose the aircraft as a means of transport depending on the business sector, and also, possibly, the formulation of the hierarchy of enterprises according to the degree of utilization of the air transport system.

In the logical scheme of the proposed work, the third stage concerns the analysis of secondary impacts, which are identified, as indicated above, with the advantages gained by business users of air transport in relation to the creation of a hub airport. In this context it is appropriate to make a reconnaissance of companies whose organization has been improved thanks to the air transport system, and those where the market and, consequently, the turnover has been extended for the same reason.

The fourth step to consider is that relating to the impacts determined from tertiary and you can highlight the location of industries in the area over gravitating and creation of jobs. In this framework, a budget should be made between positive and negative aspects related to the airport facility, with particular reference to the reflections on industrial and will also proceed to the division of business attracted from sectors of activity, the evaluation of these dependencies by air transport system, and the manner in which the firms themselves fit into the regional economic framework.

As for the jobs linked to the airport, they should be made a subdivision on the criteria already used for professional groups, and finally to a breakdown as assessed according to needs and availability in the region [5].

A reference to the changes that the airport can bring to the radius of action of the city and, in general, the level of regional life, should not be neglected in this phase.

The fifth and final step in the study of economic and social viability of a regional airport, concerns the social costs. In this respect we should carefully analyze its impact on the environment, for example, in terms of noise and air pollution. Also to determine the resources required for the performance, and assess the outputs achieved by verifying the results of conformity with the principles and objectives of regional policy. 


\section{THE SITUATION IN SICILY}

Air transport may be the mode of transport most appropriate to solve the problem of Sicily and the remoteness of its production centers from the main European markets.

The insularity and the position of marginality in Sicily compared to major Italian and European (and in general, international) air transport are essential for the growth of the island. Even in the field of aviation there are deficiencies in infrastructure and the allocations are below the national average. There is a little integration of airport facilities with other transport networks [6].

Air travel is certainly preferable to other methods of transportation for distances exceeding $800 \mathrm{~km}$, in cost/time, especially when referring to the southern regions of Italy, where it is convenient to use air travel even for routes shorter than this, above all, for the poor conditions of the alternative infrastructures such as roads and railways.

The distribution on the territory of the regional transport system acquires a primary importance, particularly in relation to the tourism sector, both in relation to the achievement of the intended purpose by the tourist and relative to the movement that this will make on the spot.

There are currently five airports operating in the Sicily region: Palermo Punta Raisi, Catania Fontanarossa, Birgi Trapani, Pantelleria and Lampedusa. Only the port of Catania can be inserted between the airports, with annual traffic exceeding 5 million, while the other 4, including Palermo Punta Raisi, which has an annual traffic of about 4.5 million passengers, are to be considered regional, including the two existing categories in the European classification (Fig. 2). The airport

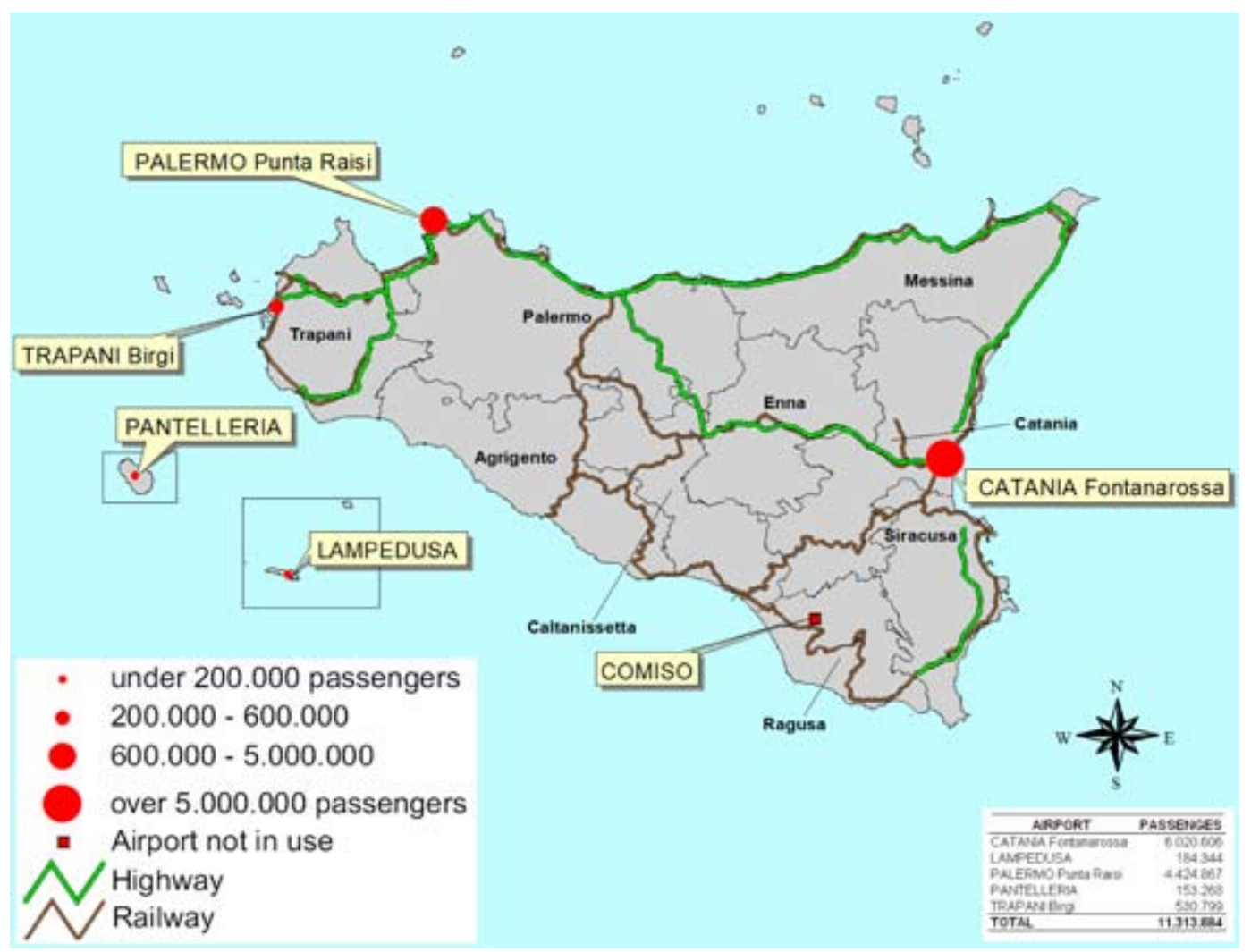

Figure 2: Sicilian Airport and passengers transported (ENAC, 2008). 


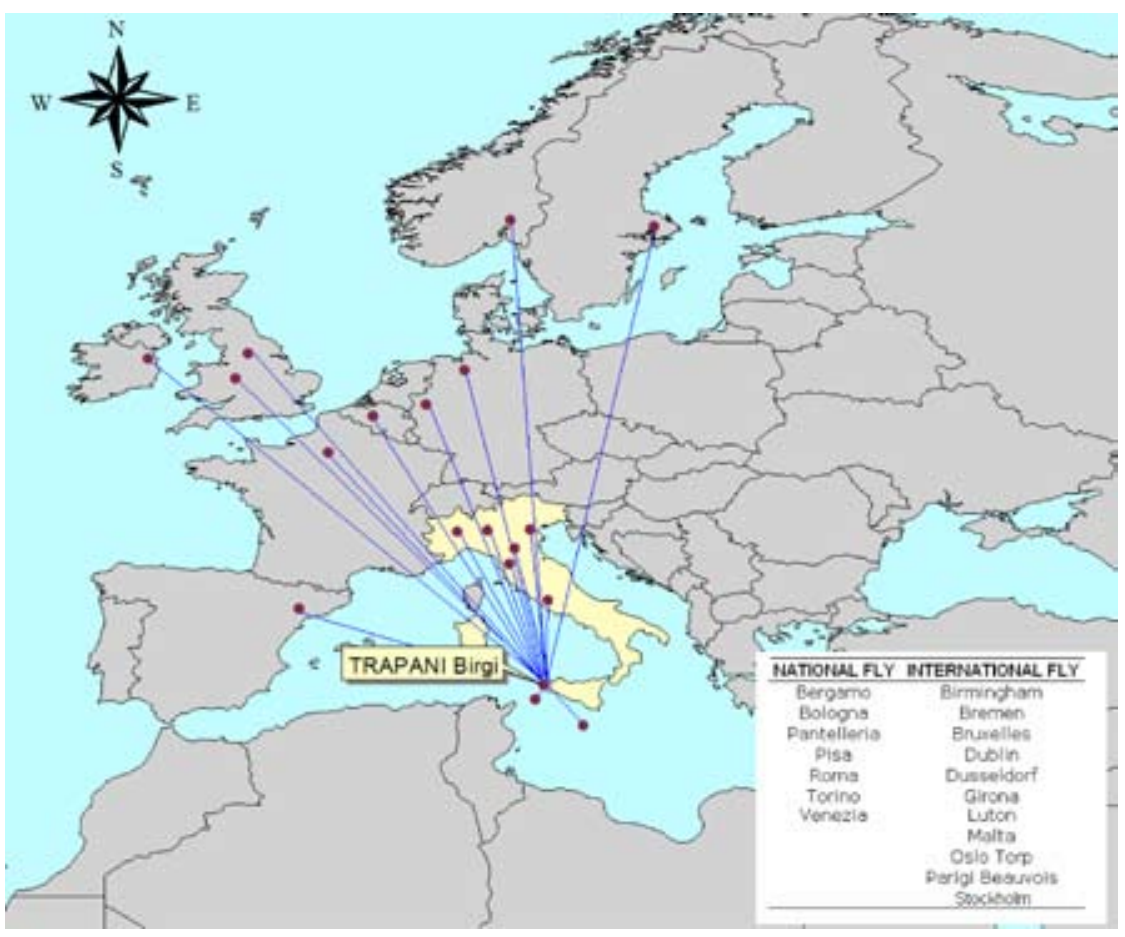

Figure 3: Trapani Birgi destinations.

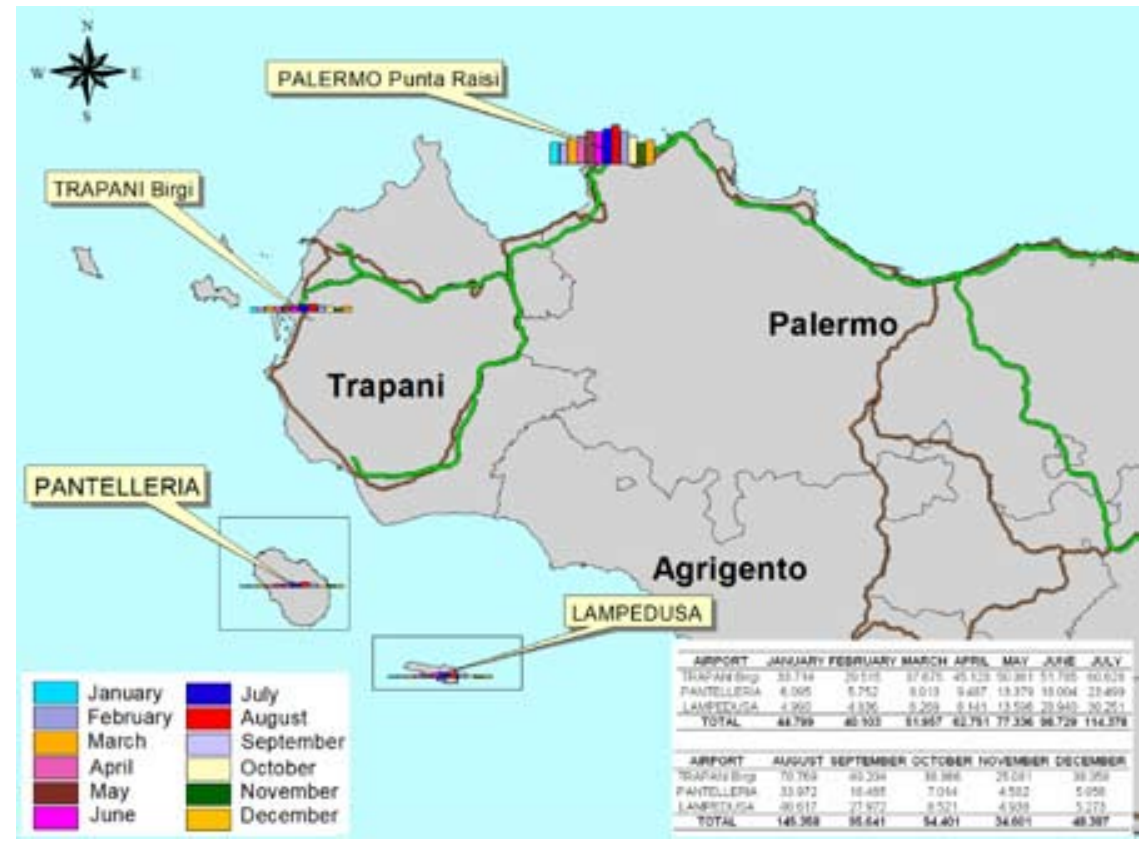

Figure 4: Number of passengers carried per month (ENAC, 2006). 
of Palermo close to the values that characterize the intermediate National, shows an area of influence than that of Catania. This is a division into two parts of Sicily, with a slightly larger portion for the airport in Catania [7].

Trapani Birgi (Fig. 3) has a limited service, most of which relate to some low-cost airlines. Pantelleria and Lampedusa have two airports basically related to tourism, and then primarily to seasonality (Fig. 4).

For these airports, there is a subsidy by the state for these flights that in addition to being a tourist service for tourists, are the only fast mode of transport for the locals who decide to travel from their island. These public service obligations, which allow airlines to make a power reduction on the ticket price for residents, aim to fill, at least in part, the social discount because of the insularity of Lampedusa and Pantelleria through an air service characterized by a low cost.

\section{REFERENCES}

[1] Dobruszkes, F., Compagnies low cost européennes et aéroports secondaires: quelles dépendances pour quel développement régional?, Les cahiers scientifiques du transports, n. 47, 2003.

[2] Lupi, M. (a cura di), Linee guida per la programmazione dello sviluppo degli aeroporti regionali, Franco Angeli: Milano, 2007.

[3] Sinatra, A. (a cura di), Aeroporti e sviluppo regionale: Rassegna di studi, Guerini e Associati: Milano, 2001.

[4] Graham, B. \& Guyer, C., The role of regional airports and air services in the United Kingdom. Journal of Transport Geography, 8, pp. 249-262, 2000. doi:10.1016/S0966-6923(00)00021-1

[5] Giordano R., Il ruolo del trasporto aereo per uno sviluppo territoriale diffuso, Franco Angeli: Milano, 1990.

[6] Giblin, J.C., Les aéroports régionaux à la veille de la décentralisation, Hérodote, n. 114, La Découverte, $3^{\circ}$ trim., 2004.

[7] ENAC (Ente Nazionale per l'Aviazione Civile), Annuario statistico 2008, Roma, 2009. 